\title{
Mechanisms of the sustainable development of non-profit organizations in the region
}

\author{
Elena Dvoryadkina*, and Dina Prostova \\ Ural State University of Economics, 8 Marta/Narodnoy Voli St., 62/45, 30, 620144 Ekaterinburg, \\ Russia
}

\begin{abstract}
This research is focused on the main mechanisms of sustainable development in relation to non-profit organizations (NPO) activities. New laws were adopted, new players appeared on the social field, the social climate was transformed and all these factors, including a number of other influences, made many traditional issues reformulated. Thus, the attention of researchers was focused on the problem of sustainability of non-profit organizations. The authors have reviewed two mechanisms for sustainability of non-profit organizations in their work: 1) financial and 2) organizational. The analysis of the components of factors of NPOs' financial stability in the region was carried out, as well as the components of the organizational mechanism. Sustainable NPO development in the region is a response to the human society's need to develop qualitatively, but rather than quantitatively, and in accordance with the constraints resulting from the region's environment. "The advantage of non-profit organizations is their focus on market behavior, taking into account the specifics of the region, while fully meeting the needs of the founders in performing socially necessary works and services, as well as a high level of independence in making operational decisions, while" [1] subordinating to the strategic targets of the founders.
\end{abstract}

\section{Introduction}

The third sector makes an invaluable contribution to the regional economy. "According to the legislation of the Russian Federation, a non-profit organization is an organization which does not have profit extraction as the main purpose of its activity and does not distribute the profit gained among its participants"[1]. In fact, it is very important that the non-profit organization is profitable to support activities that are consistent with its mission. Profit (from operations or donations) is invested in capital expenditure, such as premises and equipment, or income-generating assets to secure financing for future operations. Nonprofit organizations increase the efficiency of the social services system. NPOs contribute to social and political stability of the region. The analysis of the functioning of NPOs shows that these organizations have great potential to address social and economic issues such as supporting small and medium-sized businesses, increasing employment, increasing productivity and stimulating innovation [2]. Ultimately, NPOs, while carrying out their

\footnotetext{
${ }^{*}$ Corresponding author: elena.dvoryadkina@yandex.ru
} 
activities, have a significant impact on the sustainable development of the economy as a whole, as well as on the social and political stability of both the country as a whole and of individual regions, by adapting the community to market conditions during the transition periods of the state economy, which we are currently having in Russia [3].

The whole world (governments, business and NGOs) is now working in line with 17 sustainable development goals until 2030. 193 UN member states, including Russia, have adopted these purposes. Sustainable development goals are the most fashionable direction in 2019 for Russian companies; it is in line with these aims that they now build their charity programs and work with non-profit organizations. Many international NPOs and foundations are implementing their strategies in line with the 17 sustainability targets. The main issues are ending poverty, ensuring food security and improving nutrition, ensuring healthy lifestyles and ensuring inclusive and equitable quality education.

"The advantage of non-profit organizations in relation to commercial and state structures in the provision of social services to the population is also the individual approach to the problems and target audience. The state, which is based on the scale of its activity, may orientate itself exclusively towards the "median" consumer. NPOs are able to generate more diverse types of benefits and more successfully cope with the task of meeting the needs of even very small groups of people" [4].

"There is no doubt about the importance of issues related to the sustainable development of NPOs in today's marketplace as organizations that are able to respond quickly to the changing needs of social groups and social challenges and act effectively at the earliest stage of their inception" [1]. The non-profit organization is initially an agent of influence and development of the regional economy, an expert, an actor, an executor and a visionary. Each NPO interacts with the local community, responding subtly to the specifics of the region, taking into account the attitudes and needs of different groups. NPO is the nerve of local society development. Recently NPOs have occupied an increasingly significant position in the regional economy, extending their services and goods to the part of the population that remains outside the scope of various social services and government agencies in particular.

\section{Methods of investigating sustainability mechanisms of a non- profit organization}

The research in this paper is based on approaches and conceptual approaches of economic theory, regional economics and strategic management of the nonprofit organization. The methodological basis is a combination and synthesis of system approaches. The methods of theoretical and empirical research, in particular, the method of analysis and synthesis, the method of analogies, the method of analogies, as well as a systematic analysis of approaches to identify mechanisms of sustainable development of non-profit organizations were taken as a basis for this study. The research was informed by decrees of the President of the Russian Federation, resolutions of regional government bodies, districts and regions, data from the State Statistics Committee, as well as publications of scientific periodicals (Russian and foreign authors). The scientific significance of this work lies in complementing the theory of sustainable development of non-profit organizations and optimizing mechanisms of organizational sustainability development during the global instability of the world economy and, as a result, its impact on regional economic development. 


\section{Analysis of financial and organizational mechanisms of NPO sustainability}

Sustainability of a company is generally understood to mean its ability to keep its performance within acceptable limits for a certain period of time, even if external conditions do not allow its current operations to be economically efficient. Sustainability does not mean stability as absence of deep changes, but efficiency and reliability of the company's work as a system phenomenon.

The sustainability of a non-profit organization is determined by many characteristics, such as: the number of people who are ready to invest personal time, energy and funds in the organization's activities; loyal organizations-partners and consumers; quality of management and correct assessment of its own effectiveness; qualifications of employees and volunteers, a well-formed information field, promotion on the Internet, interaction with the media; publication of annual reports; entry into registers of various directions; relatively long term of existence; the amount of funds allocated, grants, subsidies, donations.

Sustainable development mechanisms of NPOs can be divided into two categories, financial mechanisms and organizational ones.

Financial resources, their types, sources of formation, methods of formation and use are typical for all subjects of financial relations, can be referred to the category "financial mechanism".

The financial mechanism includes financial resources, their types, sources, methods of formation and use.

Financial mechanism is an ambiguous and complex concept.

A number of Russian researchers, who use various approaches to study the financial mechanism of NPOs' sustainability, note a rather "complicated situation when studying all its components, which in some cases do not complement each other but are contradictory.

Two main groups that share the authors' views on the structure of the financial mechanism can be identified" [5] after studying the bulk of Russian school research:

1) the main focus is on the substance of the mechanism;

2) the main focus is on the elements of the financial flow management system.

Combining these two approaches, the authors in this research paper suggest that the financial mechanism of NPOs should be viewed as a system of interrelated and "complementary types and forms of organization of financial relations, as well as methods of obtaining and using financial resources, including methods of their summary definition" $[5,6]$.

Financial mechanisms of NPOs and commercial organizations have a number of common similarities in many respects. But taking into account the specifics of NPOs' activities, conditions of receipt and use of financial and material resources, financial mechanisms will have obvious differences, including freedom and autonomy in the ways of using available funds. The specifics of NPO activity are more based on funds received from sponsors, philanthropists, state support, subsidies, grants, budget funds, including regional funds, aimed at the implementation of various projects; these funds significantly prevail over "revenues from the sale of goods and services produced by NPOs. The type, ways and methods of using financial and material resources are determined in accordance with the type of economic activity of a non-profit organization" [7] and the decision of its founders.

According to the described specifics of NPOs and the prevalence of incoming funds over the company's profit, it can be concluded that it is impossible to maintain the financial stability of an organization without attracting financial and material incoming funds.

The financial mechanism of the non-profit organization depends on the type of economic activity of the organization and its members with whom it enters into financial relations, as well as on the legal form of the NPO. A non-profit organization may enter into 
financial relations with all economic entities, including public legal entities, organizations, both commercial and noncommercial, and households.

Interaction with government and local self-governance bodies can manifest itself primarily in the attraction of budget resources in the form of revenues for the organization of an NPO's statutory activities and ensuring its financial sustainability. "The sources of such revenues are funds from budgets of state and local governments in the form of subsidies, grants and budgetary investments. Distinctive feature of all NPOs, regardless of the type of economic activity, is the fact that it is impossible to maintain financial stability without attracting proceeds" [8].

Most of the financial resources of NPOs are raised through the financial method, which is used mainly on a non-refundable and non-repayable basis. It includes the attraction of budgetary sources of financing in the form of subsidies, grants, budget investments, in the event of attracting voluntary property contributions and donations, as well as the accumulation of regular and non-recurrent income from the founders of the relevant organizational and legal forms of NPOs. If there are no restrictions in the charter and legislation, the financial method is used by non-profit organizations to generate income from their activities that generate income. All NPO capitalization is also generated by using this method. For NPOs, the financial method of forming financial resources is the main one in economic practice and the only one in the theory of finance.

Sustainability of funding undoubtedly plays a fundamental role in this process. Typically, organizations that rely on one type of resource mobilization (sometimes just membership fees) do not exist for long periods. In recent years, there has been a noticeable and steady growth of financial support to non-profit organizations from state and local budgets in Russia. According to the results of the All-Russia NPO Survey, 39\% of the surveyed NPOs have one source of financing, two sources - 27\%, 3-4 sources - $25 \%, 5$ sources and more $-7 \%$ of the surveyed NPOs. In general, there were no sources of funding for only $2 \%$ of NGOs, $2 \%$ of NGOs live only at the expense of personal funds of members, participants, founders of the organization, which are not contributions. It shows the orientation of Russian NPOs towards diversification of funding sources. A non-profit organization can determine what types of income it can attract for its activities. It is optimal to rely on several sources so that the organization can cover both administrative and project costs. Individual set of different sources and percentage of income depends on a number of factors, such as: skills and resources of the organization, subject matter of its work, regional peculiarities, etc. [9].

"In general, it should be noted that elements of the NPO financial mechanism are traditional, but their content includes a number of distinctive features. The financial mechanism is noticeably influenced by the variety of financial relations, types of economic activities and organizational and steam forms of NPOs, which predetermine some features of individual elements of their financial mechanism"[5].

Support from regional authorities plays an essential role in the financial stability of NPOs. For example, the Sverdlovsk Oblast Government has developed comprehensive programs to support socially oriented non-profit organizations (SONPO):

In 2014, the Government of the Sverdlovsk region adopted a Resolution of 19.02.2014 N 100-PP "On approval of the Sverdlovsk region Comprehensive Program" Support for socially oriented non-profit organizations in the Sverdlovsk region in 2014 - 2016 years [10].

The Program activities were planned to be implemented from the federal and regional budgets, as well as from extra-budgetary funds in the amount of 379,509.0 thousand rubles, including: 2014 - 139,895.1 thousand rubles; 2015 - 127,743.2 thousand rubles; 2016 $111,870.7$ thousand rubles. 
In 2018, the Sverdlovsk Region Government Resolution No. 328-PP of 31.05.2018 approved the Sverdlovsk Region Comprehensive Program "Support of socially oriented non-profit organizations in the Sverdlovsk Region for 2018-2024" [11].

The "organizational mechanism" category can include internal and external processes, namely, human resources and organizational policy of the NPO, strategy development and implementation of activities to achieve the mission of the organization, through quality planning and flexibility of management. It becomes possible due to attraction of highly qualified specialists and consultants - managers, fundraisers, lawyers, accountants, specialists in organizational development, on whose professionalism strategic and financial planning of the organization depends. This category also includes training of staff, as well as volunteers. It should be noted that financial mechanisms and organizational mechanisms are interconnected, strengthening of financial stability, and they will attract professional staff, including through a decent level of remuneration of these specialists.

Organizational processes in NPO management are traditionally considered "secondary". However, errors and lack of understanding of the organizational component in the activities and development of NPOs often cause the failure of a number of promising and important ideas for society and often lead to the liquidation of organizations due to the failure of the mission for which they were created. Organizational processes within non-profit organizations should be sensitive to the changing situation in the country and the regions where they are located and should timely make a number of changes to meet increasingly new market requirements [12].

For the purpose of successful organizational development of NPOs it is recommended to follow the following algorithm of actions:

- study the basic concepts related to organizational development of non-profit organizations;

- analyze the formulation of the NPO's mission and its objectives, and in accordance with them, determine the directions of the NPO's organizational development;

- to get acquainted with the situation in the region and to analyze perspective directions of NPO's work depending on the situation in the territory of NPO's location and functioning;

- master the principles of the non-profit organization's activity;

- study the specifics of strategic and operational (current) management with the purpose of organizational development of the non-profit organization;

- become acquainted with the peculiarities of human resources management in a nonprofit organization;

- $\quad$ study the specifics of financial management in NPO;

- learn how to strengthen a non-profit organization's material base.

- Thus, for successful organizational development of the non-profit organization, it is necessary to familiarize with the priorities of NPO financing in the region.

\section{Conclusions}

The authors discussed the mechanisms of sustainable NPOs' development, namely, financial and organizational mechanisms in this paper. The review of the literature showed that despite the growing interest in the sustainability of the organization, this issue was considered in a fragmented manner in the scientific literature. As shown in case studies and confirmed by existing literature, in response to the growing competitive environment, NPOs were forced to pay attention to financial and organizational sustainability at both the strategic and operational management levels. 
As a result, an algorithm of NPO performance evaluation is formed, which is based on the general principles of each element of the financial mechanism defined by the financial plan of NPO development [5].

The review allows us to identify a number of areas in NPO activities aimed at their sustainable development and contributing to the sustainable development of the region:

- promoting economic integration and forming a positive image of the region;

- work within the framework of consolidation of Russian regions and promotion of closer humanitarian links;

- $\quad$ work with scientific, educational and expert environment;

- actualization of problems in regions with unfavorable social and political situation;

- work with the youth audience in order to raise awareness of the importance of addressing regional socio-economic issues.

- work with local businesses, involving entrepreneurs in charity and social projects, improving the image of NPOs, thus increasing their credibility with society and, as a result, the profit of these organizations;

- working with local authorities;

- participation of non-profit organizations in grant contests and participation in federal, republican and municipal programs aimed at regional development;

- interaction with the local administration as an independent participant in initiative budgeting projects or as a partner.

There is no doubt that it is difficult to overestimate the importance and relevance of these activities in the current conditions.

Thus, this research contributes to the development of NPOs in the regional economy. Defining the importance of sustainability as a central issue in NPO governance and proposing the need for sustainability as a key aspect in conceptualizing and measuring the theory of social entrepreneurship. The study contributes to the current debate about whether NPOs should remain strictly in the non-profit sphere and whether business should remain focused solely on profit strategies and whether current climate change will not provide onlyfavorable opportunities for new business but also new business models.

\section{References}

1. E.A. Sesyavin, Development of state support mechanisms for targeted non-profit organizations at the regional level, http://www.dslib.net/

2. F.S. Cinpaeva, The role of non-profit organizations in the development of the region, https://cyberleninka.ru/

3. N.B. Golovanova, Management of economic systems: electronic scientific journal, 8 (2013)

4. D. Billis, H. Glennerster, Journal of Sources of Government Growth, NC (1998)

5. S.V. Frumina, T. Yu. Kiseleva, S.S. Dzusova, Features of the financial mechanism of non-profit organizations, https://www.elibrary.ru/

6. I.V. Ishina, S.V. Frumina, Revealing the features of the mechanism for the implementation of financial policy in an innovative economy, https://www.elibrary.ru/

7. A.V. Marzaev, N.P. Molchanova, T.Yu. Kiseleva, I.S. Ryabova, V.V. Zavgorodnyaya, I.N. Molchanov, A.Yu. Chernov, S.S. Dzusova, O.N. Dolina, N.A. Guz', Theory and practice of finance for non-profit organizations, https://elibrary.ru/

8. S.V. Frumina, Scientific Review, 10, 127 (2014)

9. N.Yu. Izyumchenko, NPO sustainability - key factors, https://nko-pfo.ru/ 
10. Decree of the Government of the Sverdlovsk Region of 19.02.2014 N 100-PP "On approval of the Comprehensive Program of the Sverdlovsk Region; Support of socially oriented non-profit organizations in the Sverdlovsk Region for 2014 - 2016", http://docs.cntd.ru/

11. Comprehensive program of the Sverdlovsk region "Support of socially oriented nonprofit organizations in the Sverdlovsk region for 2018 - 2024", http://docs.cntd.ru/

12. Organizational development of NPO, https://belnko.ru/ 